\title{
Home-Based Subcutaneous Immunoglobulin G Replacement Therapy under ReAl-Life Conditions in ChILDREn AND Adults with ANTIBODY DEFICIENCY
}

\author{
F. Hoffmann ${ }^{1}$, B. Grimbacher ${ }^{2}$, J. Thiel ${ }^{2}$, H.-H. Peter ${ }^{2}$, B. H. Belohradsky ${ }^{1}$ \\ and the Vivaglobin ${ }^{\circledR}$ Study Group
}

${ }^{1}$ University Children's Hospital, Paediatric Infectious Diseases and Immunology, Ludwig Maximilians University, Munich, Germany,

${ }^{2}$ University Hospital, Immunology and Rheumatology, Centre of Chronic Immunodeficiency, University of Freiburg, Germany

\begin{abstract}
Background: Subcutaneous immunoglobulin (SCIG) therapy is an alternative to intravenous immunoglobulin (IVIG) therapy.

Methods: We evaluated the efficacy and safety of the SCIG Vivaglobin ${ }^{\circledR}$ (formerly known as Beriglobin ${ }^{\circledR}$ $\mathrm{SC})$ under real-life conditions in a post-marketing observational study in 82 patients with primary or secondary antibody deficiencies. Health-related quality of life (HRQoL) was evaluated in a subset of 30 patients previously treated with IVIG (including 11 children $<14$ years) using the Short Form 36 (SF-36) for patients $\geq 14$ years of age (adults) and the Child Health Questionnaire - Parental Form 50 (CHQ-PF50) for children $<14$ years of age. Treatment preferences were assessed in adults.

Results: The mean serum immunoglobulin G ( $\mathrm{IgG}$ ) trough level during SCIG treatment $(7.5 \mathrm{~g} / \mathrm{L})$ was higher than during previous IVIG treatment $(6.6 \mathrm{~g} / \mathrm{L}$; $\mathrm{p}<0.01)$. The investigators assessed the efficacy of SCIG therapy as "excellent" in $89 \%$ of patients. No systemic adverse drug reactions were observed. Improvements by $\geq 5$ points were observed in 5 of $8 \mathrm{SF}$ 36 subscales and in 6 of 12 CHQ-PF50 subscales. Statistically significant improvements $(\mathrm{p} \leq 0.05)$ were observed for the SF-36 subscales of bodily pain, general health perceptions, and vitality (adults), and for the CHQ-PF50 subscales of general health perceptions, parental impact - time, parental impact - emotional, and family activities (children). Patients preferred SCIG over IVIG therapy $(92 \%)$ and home therapy over therapy at the clinic/physician (83\%).

Conclusion: This study confirms that therapy with Vivaglobin ${ }^{\circledR}$ at home is effective, safe, well tolerated, and improves quality of life in patients with antibody deficiency.
\end{abstract}

Key words: antibody deficiency, subcutaneous immunoglobulin therapy, quality of life, children, adults

Abbreviations: CHQ-PF50: Child Health Questionnaire - Parental Form 50; HRQoL: health-related quality of life; IgG: immunoglobulin G; IVIG: intravenous immunoglobulin; SCIG: subcutaneous immunoglobulin; SF-36: HRQoL questionnaire Short Form 36

\section{INTRODUCTION}

Primary antibody deficiencies belong to the wide range of primary immune deficiency diseases caused by intrinsic or genetic defects in the immune system $[1,2]$. They comprise a range of inherited disorders that are characterized by defects in antibody production and/or function. Common variable immunodeficiency, which is the most common of the more severe primary immunodeficiencies, is associated with recurrent or chronic infections of the respiratory tract $(>95 \%)$ and the gastrointestinal tract (approximately $50 \%)$, as well as with autoimmune phenomena $(20 \%$ to $30 \%$ ), splenomegaly (approximately 30\%), noncaseating granulomas (approximately 10\%), and malignancies $[3,4]$.

Patients suffering from primary antibody deficiencies require lifelong regular immunoglobulin infusions $[2,5]$. Nowadays, subcutaneous immunoglobulin (SCIG) infusions are used as an alternative to intravenous immunoglobulin (IVIG) administration in adults and children with primary or secondary antibody deficiencies $[6,7]$. SCIG infusions were shown to be efficacious, safe, and well tolerated [8]. They are also appreciated by adults and children for their ease of administration [8, 9]. Few systemic adverse reactions have been reported during SCIG infusions, indicating a favourable safety profile compared to intravenous or intramuscular administration of immunoglobulin $[10,11]$. The average serum levels attained during SCIG therapy are comparable to those attained during IVIG therapy, but with reduced oscillations between consecutive infusions $[9,12,13]$.

Home-based SCIG treatment is convenient because fewer visits to the clinic or physician are required than with IVIG therapy, which is not licensed as home treatment in Germany. The safe and easy-to-use SCIG infusion technique [14] supports SCIG home treatment as an alternative to IVIG therapy $[15,16]$.

A possible increase in quality of life is another important aspect of home-based SCIG treatment. Only limited data on self-reported outcomes in health-related quality of life (HRQoL) in adults and children with primary antibody deficiencies receiving replacement therapy are available $[17,18,19,20,21]$. However, 
where available, these data revealed significant improvements in quality of life in patients switching from IVIG therapy at the hospital to SCIG therapy at home.

The first immunoglobulin $G(\mathrm{IgG})$ preparation specifically approved for subcutaneous administration, Vivaglobin ${ }^{\circledR}$ (formerly known as Beriglobin ${ }^{\circledR}$ SC; CSL Behring, Marburg, Germany), was licensed in Germany in December 2002 and in the USA in January 2006. SCIG infusions have also been used in Scandinavian countries for nearly 20 years in the treatment of antibody deficiencies, and home-based SCIG therapy is now the standard of care in many countries [22].

The aims of this post-marketing observational study were to evaluate the efficacy and safety of SCIG replacement therapy with Vivaglobin ${ }^{\circledR}$ under real-life conditions in adults and children with primary or secondary antibody deficiencies, and to describe HRQOL in this population.

\section{METHODS}

\section{STUdy Design}

This was a prospective, observational, multicentre study conducted in Germany. The study design involved 7 visits to the clinic or physician during the 9month study period (visits 1 to 4 were monthly, subsequent visits were every 2 months). For patients previously treated with IVIG, baseline data obtained before the first administration of Vivaglobin ${ }^{\circledR}$ at visit 1 , reflecting conditions during prior IVIG therapy, were compared to data obtained at the follow-up (visit 7) after 9 months of treatment with Vivaglobin ${ }^{\circledR}$.

Patients with primary or secondary antibody deficiencies were eligible for the study, with no age limit specified. Efficacy and safety evaluations were based on all 82 patients enrolled in the study. HRQoL was evaluated only in patients who had been on IVIG therapy before enrolment. If patients had missing data for specific endpoints, they were excluded from the analyses of those endpoints.

\section{TREATMENT}

Vivaglobin ${ }^{\circledR}$ was used as a ready-to-use pasteurized liquid containing polyvalent human $\operatorname{IgG}$ at a concentration of $160 \mathrm{mg} / \mathrm{mL}$ (16\%). Subcutaneous infusions were administered using small, battery-driven syringe drivers as described by Gardulf et al. [9].

A weekly SCIG dose of 100 to $200 \mathrm{mg} / \mathrm{kg}$ body weight is considered sufficient to achieve serum $\operatorname{IgG}$ levels within the normal range in adults and children $[11,23]$. In patients who received IVIG therapy before enrolment, the monthly IVIG dose was divided by 4 to calculate a corresponding weekly dose for SCIG therapy. Patients who received weekly SCIG infusions before enrolment continued with the same weekly dose.

All patients and parents or guardians were trained in the subcutaneous administration of Vivaglobin ${ }^{\circledR}$ during 4 to 6 training sessions at the clinic or physician's office. Patients had to demonstrate skill, knowledge, and confidence in SCIG administration before the therapy could be self-administered at home; parents or guardians gave the infusions to their chil- dren or supervised their children's self-administration of SCIG.

\section{STudy Outcomes}

The efficacy and safety analysis included all enrolled patients with available data. The HRQoL analysis included all patients who had been receiving IVIG therapy before enrolment and who had completed their HRQoL questionnaire at baseline within 2 weeks of starting Vivaglobin ${ }^{\circledR}$ administration and at the final assessment (visit 7). Missing data for an entire assessment (i.e., missing forms) were not imputed.

\section{SERum IgG TROUGH LeVELS}

Serum IgG trough levels measured within 2 months before study start were recorded at baseline. During the study, blood samples were drawn for the analysis of serum IgG trough levels. For patients previously treated with IVIG, serum IgG trough levels during SCIG therapy with Vivaglobin ${ }^{\circledR}$ at visits 4 and 7 were compared to trough levels measured during IVIG treatment within 2 months prior to study start and 3 to 4 weeks after an IVIG infusion.

\section{EFFICACY}

At the final assessment scheduled after 9 months of treatment, the investigator assessed the outcome of the SCIG therapy in terms of its efficacy using categories of "excellent", "acceptable", and "insufficient". In addition, the investigators assessed the feasibility of patients learning to use the treatment as a home-based therapy. Patients were asked how flexible they thought the SCIG therapy was compared to IVIG therapy (more, the same, or less flexibility).

\section{HeALTh-ReLated Quality of Life (HRQoL)}

Patients who had previously been on IVIG therapy completed HRQoL questionnaires at study start (baseline) and at the final assessment (follow-up). The patients or their parents or guardians gave informed consent to the scientific processing of their data.

The HRQoL questionnaire Short Form 36 (SF-36) was used for patients older than 14 years (i.e., adolescents and adults, hereafter referred to as adults). The SF-36 consists of 35 items forming 8 subscales measuring physical and mental health (Table 1) [24, 25]. The 1-year comparison of health item was excluded because the study assessment period was less than 1 year. Higher scores indicate a better HRQoL (possible scores: 0 to 100$)$.

The Child Health Questionnaire - Parental Form 50 (CHQ-PF50) was used for patients younger than 14 years and was answered by their parents or guardians [26]. This questionnaire focuses on the physical and psychosocial functioning and well-being of the child and the child's family. It consists of 50 items forming 12 subscales (Table 2) [19]. As for the SF-36 questionnaire, the global item change in health was not used because of the 1-year recall period. Higher scores indicate a better HRQoL (possible scores: 0 to 100). 
Table 1. Scales of the HRQoL questionnaire Short Form 36.

\begin{tabular}{|c|c|c|}
\hline SF-36 scale & Number of items & Description \\
\hline \multicolumn{3}{|l|}{ Physical health } \\
\hline Physical functioning & 10 & Limitations in various physical activities \\
\hline Role physical & 4 & Problems with work or other daily activities as a result of physical health \\
\hline Bodily pain & 2 & Limitations due to pain \\
\hline General health perceptions & 5 & Evaluation of personal health \\
\hline \multicolumn{3}{|l|}{ Mental health } \\
\hline Vitality & 4 & Energy and fatigue \\
\hline Social functioning & 2 & $\begin{array}{l}\text { Interference with normal social activities due to physical and emotional } \\
\text { problems }\end{array}$ \\
\hline Role emotional & 3 & $\begin{array}{l}\text { Problems with work or other daily activities as a result of emotional } \\
\text { problems }\end{array}$ \\
\hline Mental health & 5 & Psychological distress and well-being \\
\hline
\end{tabular}

Table 2. Scales of the Child Health Questionnaire - Parental Form 50.

\begin{tabular}{|c|c|c|}
\hline CHQ-PF50 scale & Number of items & Description \\
\hline \multicolumn{3}{|l|}{ Physical } \\
\hline Physical functioning & 6 & $\begin{array}{l}\text { Limitations in physical activities such as walking, bathing, and } \\
\text { strenuous sports }\end{array}$ \\
\hline Role physical & 2 & $\begin{array}{l}\text { Limitations in school-related activities and activities with friends as } \\
\text { a result of physical health }\end{array}$ \\
\hline Bodily pain & 2 & Intensity and frequency of general pain or discomfort \\
\hline General health perceptions & 6 & Perception of overall health status \\
\hline \multicolumn{3}{|l|}{ Psychological } \\
\hline Role emotional/behavioural & 3 & $\begin{array}{l}\text { Limitations in school, work, or activities with friends as a result of } \\
\text { emotional or behavioural problems }\end{array}$ \\
\hline Behaviour & 6 & $\begin{array}{l}\text { Ability to get along with others and behavioural problems including } \\
\text { aggression, delinquency, hyperactivity or impulsivity, and social } \\
\text { withdrawal }\end{array}$ \\
\hline Mental health & 5 & $\begin{array}{l}\text { Both negative and positive states including anxiety, depression, and } \\
\text { positive effect }\end{array}$ \\
\hline Self esteem & 6 & $\begin{array}{l}\text { Satisfaction with school and athletic ability, looks or appearance, } \\
\text { ability to get along with others and family, and life overall }\end{array}$ \\
\hline \multicolumn{3}{|l|}{ Parental impact } \\
\hline Parental impact - emotional & 3 & $\begin{array}{l}\text { Distress and worry experienced by parent regarding child's } \\
\text { condition }\end{array}$ \\
\hline Parental impact - time & 3 & $\begin{array}{l}\text { Limitations in personal time experienced by parent due to child's } \\
\text { conditions }\end{array}$ \\
\hline \multicolumn{3}{|l|}{ Family } \\
\hline Family activities & 6 & $\begin{array}{l}\text { Limitations and interruptions in usual family activities and family } \\
\text { tension as a result of child's health }\end{array}$ \\
\hline Family cohesion & 1 & Ability of family members to get along with one another \\
\hline
\end{tabular}

Patients (or parents/guardians) assessed the health status on a visual-analogue scale ranging from 0 (worst imaginable health state) to 100 (best imaginable health state).

At follow-up, adults assessed their treatment preferences regarding the route of administration (SCIG, IVIG, or no preference) and the location of IgG therapy (at home, at the clinic/physician, or no preference).

\section{SAFETY}

Any signs of SCIG-related systemic adverse reactions were documented. At each visit, blood samples were taken for laboratory tests (haematology and chemistry), and a physical examination was performed. Safety data were analysed descriptively for all patients who had received at least 1 infusion of Vivaglobin ${ }^{\circledR}$.

\section{STATISTICAL ANALYSIS}

Categorical data are presented using frequencies (number, percentage), and continuous data are presented using mean, standard deviation (SD) or standard error (SE), median, and maximum and minimum values. For comparison of data obtained at baseline and at the final visit, the Student's paired t-test was used. Statistical 
Table 3. Demographic and medical data.

\begin{tabular}{|c|c|c|}
\hline \multirow[b]{2}{*}{ Variable } & \multicolumn{2}{|c|}{ Population } \\
\hline & Efficacy + safety & HRQoL a \\
\hline Number of patients enrolled, $\mathrm{N}$ & 82 & $48 \mathrm{~b}$ \\
\hline Number of evaluable patients, N (\%) & $82(100 \%)$ & $30(100 \%)$ \\
\hline \multicolumn{3}{|l|}{ Sex, $n(\%)$} \\
\hline Male & $34(41 \%)$ & $19(63 \%)$ \\
\hline Female & $46(56 \%)$ & $11(37 \%)$ \\
\hline Missing & $2(2 \%)$ & 0 \\
\hline Age (years), mean (range) & $34(1-74)$ & $30(3-74)$ \\
\hline \multicolumn{3}{|l|}{ Age group, n (\%) } \\
\hline$<14$ years & $17(21 \%)$ & $11(37 \%)$ \\
\hline$\geq 14$ years & $65(79 \%)$ & $19(63 \%)$ \\
\hline \multicolumn{3}{|l|}{ Diagnosis, n (\%) } \\
\hline Common variable immunodeficiency & $44(54 \%)$ & $11(37 \%)$ \\
\hline X-linked agammaglobulinaemia (Bruton disease) & $13(16 \%)$ & $9(30 \%)$ \\
\hline Severe combined immunodeficiency & $4(5 \%)$ & $1(3 \%)$ \\
\hline IgG subclass deficiency & $4(5 \%)$ & $1(3 \%)$ \\
\hline Other congenital hypo- or agammaglobulinaemia & $5(6 \%)$ & $2(7 \%)$ \\
\hline Secondary immunodeficiency & $9(11 \%)$ & $5(17 \%)$ \\
\hline Missing & $3(4 \%)$ & $1(3 \%)$ \\
\hline \multicolumn{3}{|l|}{ Prior treatment with immunoglobulins, $\mathrm{n}(\%)$} \\
\hline Intravenous infusions & $60(73 \%)$ & $30(100 \%)$ \\
\hline Intramuscular infusions & $3(4 \%)$ & 0 \\
\hline Subcutaneous infusions & $12(15 \%)$ & 0 \\
\hline None & $6(7 \%)$ & 0 \\
\hline Missing & $1(1 \%)$ & 0 \\
\hline
\end{tabular}

a The HRQoL population is a subpopulation of the efficacy + safety population.

b Number of patients who completed the baseline HRQoL questionnaire.

significance was accepted for $\mathrm{p} \leq 0.05$. The data were processed using SAS, version 8.2 (SAS Institute Inc., Cary, NC, USA) and Microsoft ${ }^{\circledR}$ Office Excel 2003 (Microsoft Corporation, Redmond, WA, USA).

\section{RESULTS}

\section{Study Populations and Treatment}

A total of 82 patients were enrolled in the study at 24 sites in Germany. The mean age was 34 years (range: 1 to 74 years), and 17 subjects were younger than 14 years (Table 3). The mean weight was $62 \mathrm{~kg}$ (range: 10 to $117 \mathrm{~kg}$ ). The most frequent diagnoses were common variable immunodeficiency $(54 \%)$ and X-linked agammaglobulinaemia (16\%). Nine patients $(11 \%)$ had secondary immune deficiencies, with chronic lymphocytic leukaemia (4 patients) and non-Hodgkin lymphomas ( 3 patients) being the most frequent underlying diseases. The majority of the patients $(73 \%)$ had previously received IVIG, 15\% had received SCIG, 4\% intramuscular and 7\% no immunoglobulin treatment.

Overall, the 82 patients received a total of approximately 3500 SCIG infusions during the study. For the 406 infusions that were documented at the 7 study visits, the median number of infusions sites was 2 (range: 1 to 6). The most common application sites were the abdomen (84\%) and the thigh $(10 \%)$; in $5 \%$ of the cases, both of these sites were used. The mean $( \pm \mathrm{SD})$ dose was $91( \pm 31) \mathrm{mg} / \mathrm{kg} /$ week, the mean $( \pm \mathrm{SD})$ dosing volume per week was $35( \pm 15) \mathrm{mL}$, and the mean $( \pm S D)$ infusion rate was $12( \pm 6) \mathrm{mL} /$ hour. After the first visit, most infusions $(87 \%)$ were self-administered or administered by a parent or guardian.

A total of 22 patients (22 adults, no child) discontinued the study prematurely. For 8 patients, the reason for discontinuation was given (1 patient each): hospitalization for stem cell transplantation; no further IgG treatment necessary; decision of patient; adverse drug reaction; overall end of study reached before scheduled final visit of the patient; progression of underlying malignant disease; patient could not cope with subcutaneous treatment; and psychiatric disease.

A total of 48 patients completed the HRQoL questionnaire at baseline. Eighteen of these patients (13 adults and 5 children) were excluded from the HRQoL analysis because they had not received IVIG prior to study start (4 patients), or they completed the baseline HRQoL questionnaire more than 2 weeks after their first Vivaglobin ${ }^{\circledR}$ administration (8 patients), or they did not complete the follow-up HRQoL questionnaire at the final visit (6 patients). Thus, HRQoL was evaluated for 30 patients (19 adults and 11 children; Table 
Table 4. Efficacy outcomes and preferences regarding $\operatorname{IgG}$ therapy at follow-up.

\begin{tabular}{lc}
\hline Efficacy outcomes & Number (\%) of patients \\
\hline Assessment of SCIG therapy by investigator & $\mathbf{( N = 6 1 )}$ \\
Excellent & $54(89)$ \\
Acceptable & $6(10)$ \\
Insufficient & $1(2)$ \\
Final assessment of therapy by investigator & $(\mathbf{N}=\mathbf{6 1})$ \\
Easy to learn and well feasible & $50(82)$ \\
Learnable and feasible & $9(15)$ \\
Too hard to learn as home therapy & $2(3)$ \\
Final assessment of therapy by patient & $\mathbf{N}=\mathbf{4 4})$ \\
Gives more flexibility than IVIG & $38(86)$ \\
Gives the same flexibility as IVIG & $4(9)$ \\
Gives less flexibility than IVIG & $2(5)$ \\
\hline
\end{tabular}

3). For the analysis of treatment preferences, all adults who answered the questions on treatment preferences at the final visit were considered (24 patients).

\section{Outcomes}

Serum IgG trough levels

For 20 patients who had been on IVIG before Vivaglobin ${ }^{\circledR}$ treatment, serum IgG trough levels were available which fulfilled both of the following conditions: (i) measured within 2 months before study start and (ii) measured 3 to 4 weeks after an IVIG infusion. The mean serum $\operatorname{IgG}$ trough level before study start was $6.6 \mathrm{~g} / \mathrm{L}$, as compared to $7.5 \mathrm{~g} / \mathrm{L}$ at visit 4 (100 days after baseline) and at visit 7 (290 days after baseline; Fig. 1). The difference between the mean $\operatorname{IgG}$ trough level during IVIG treatment before study start compared to IgG trough levels with SCIG at visit 4 and visit 7 was statistically significant $(p<0.01$ at both evaluations), while the mean monthly $\operatorname{IgG}$ dose was not statistically different between IVIG $(0.39 \mathrm{~g} / \mathrm{kg}$ body weight; monthly administration) and SCIG $(0.37 \mathrm{~g} / \mathrm{kg}$

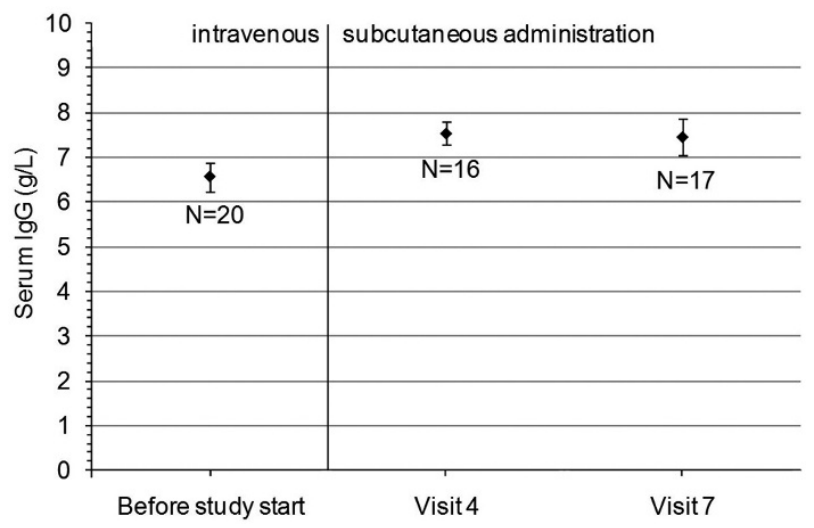

Fig. 1. Serum IgG trough levels (means and standard errors). For this analysis, 20 patients were considered who had prestudy serum $\operatorname{IgG}$ concentrations which fulfilled both of the following conditions: (i) measured within 2 months before study start and (ii) measured 3 to 4 weeks after an IVIG infusion. On average, visit 4 was 100 days and visit 7 was 290 days after baseline. body weight; administered in 4 weekly doses). The mean $( \pm$ SE) serum $\operatorname{IgG}$ trough level for all patients with available data was $7.1( \pm 0.3) \mathrm{g} / \mathrm{L}$ at visit 4 $(\mathrm{N}=55)$ and $7.2( \pm 0.3) \mathrm{g} / \mathrm{L}$ at visit $7(\mathrm{~N}=54)$.

\section{EFFICACY}

Efficacy of the SCIG therapy was evaluated by the investigators in 61 of the 82 patients treated. The SCIG therapy was assessed as "excellent" in $89 \%$ of patients (Table 4). In $10 \%$ of patients, the SCIG therapy was assessed as "acceptable", and in only 1 patient was the SCIG therapy assessed as "insufficient". The investigators considered the administration of SCIG therapy as "easy to learn and well feasible" in $82 \%$ of patients, as "learnable and feasible" in $15 \%$ of patients, and as "too hard to learn as home therapy" in only $3 \%$ of patients (Table 4). Of the 44 patients who documented their opinions on the SCIG treatment, $86 \%$ reported that the SCIG therapy gave more flexibility than IVIG therapy, 9\% stated it was the same, and 5\% stated that the SCIG therapy provided less flexibility (Table 4).

\section{Health-Related Quality of Life}

In adults, the mean SF-36 scores increased by at least 5 points between baseline and follow-up in 5 out of 8 scales, including all scales of the category physical health (Fig. 2a) and the scale of vitality in the category mental health (Fig. 2b). The improvement between baseline and follow-up scores was statistically significant for bodily pain $(\mathrm{p}=0.02)$, general health perceptions $(\mathrm{p}=0.05)$, and vitality $(\mathrm{p}=0.05)$.

The CHQ-PF50 questionnaire was completed by caregivers for children younger than 14 years. Increases of at least 5 points in the mean scores were observed between baseline and follow-up in 6 out of 12 scales, including physical functioning, role physical, and general health perceptions in the physical category (Fig. $3 a)$, both scales in the parental impact category, and the scale family activities in the family category (Fig. 3c). In the psychological category, generally no difference between baseline and follow-up was observed, except for a slight decrease in the behaviour scale, which was not statistically significant (Fig. 3b). The difference be- 

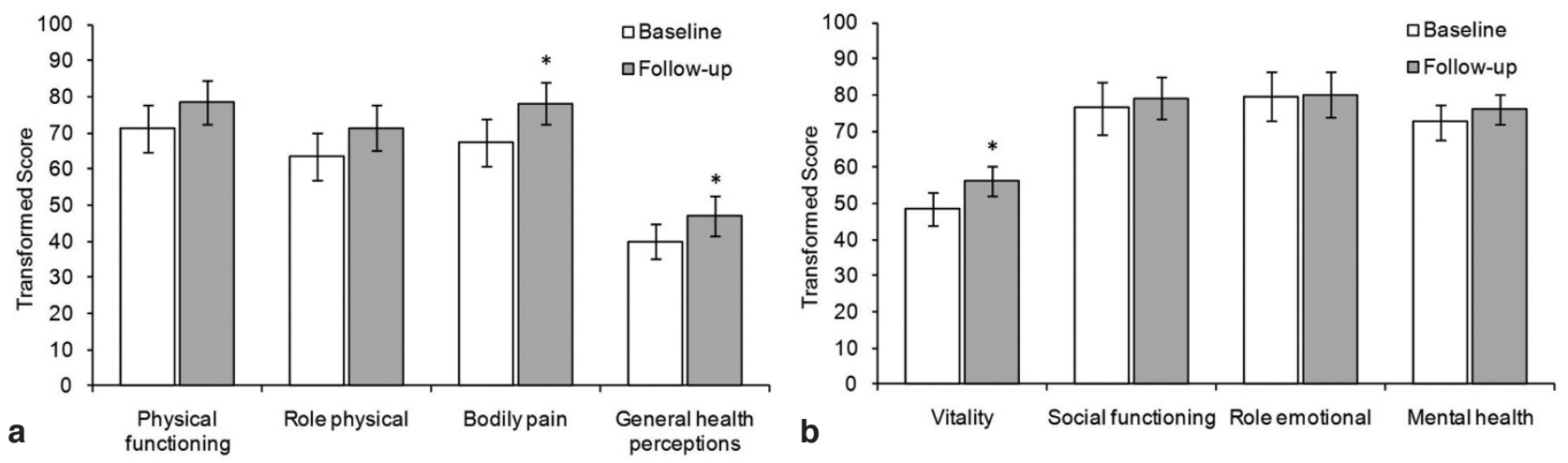

Fig. 2. SF-36 Scores for adults ( $\geq 14$ years) in the HRQoL subpopulation at baseline (visit 1) and follow-up (visit 7). Mean and standard error data are shown $(\mathrm{N}=19$, except for the scales general health perceptions and role emotional: $\mathrm{N}=18)$. A score of 0 indicates the worst possible health state and 100 the best possible health state. * Statistically significant difference between baseline and follow-up $(\mathrm{p} \leq 0.05)$. a) Physical health subscales. b) Mental health subscales.
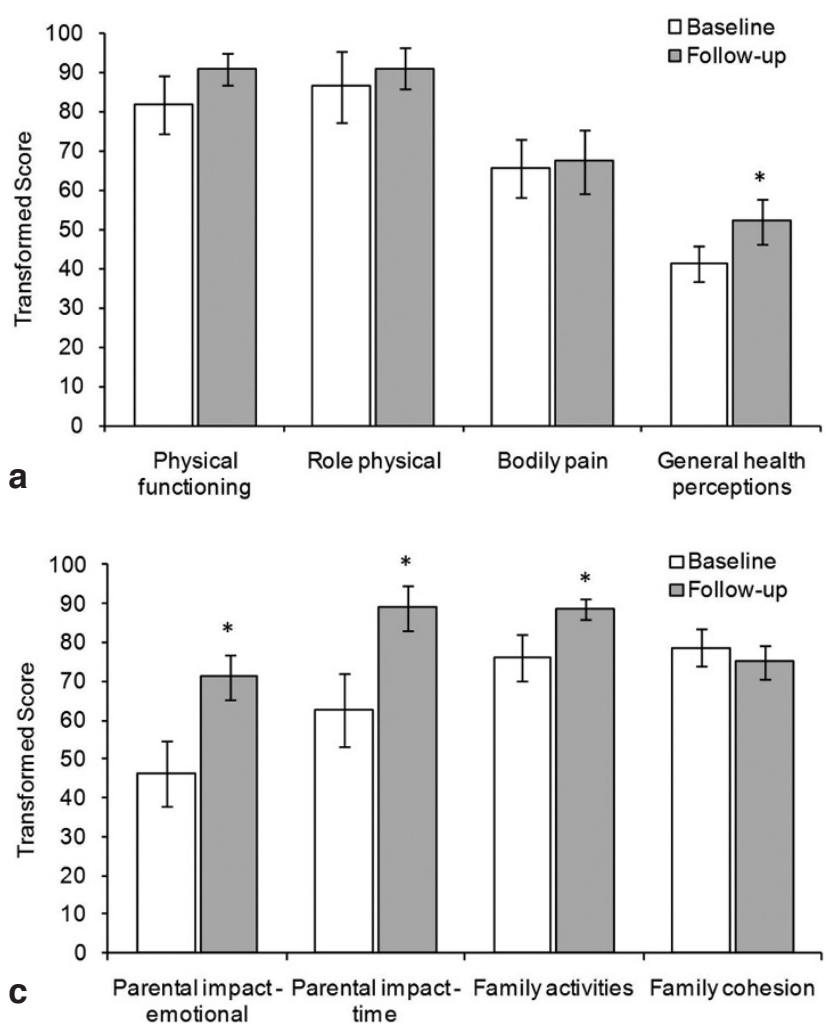

tween baseline and follow-up scores was statistically significant for general health perceptions $(\mathrm{p}=0.04)$, parental impact - emotional $(\mathrm{p}=0.03)$, parental impact time $(\mathrm{p}=0.02)$, and family activities $(\mathrm{p}=0.02)$.

The mean health status score (maximum: 100) in adults increased from 56 at baseline $(\mathrm{N}=19)$ to 69 at follow-up $(\mathrm{N}=11)$; in children, the score increased from 65 at baseline $(\mathrm{N}=11)$ to 78 at follow-up $(\mathrm{N}=11)$. However, the differences were not statistically significant.

At follow-up, $92 \%$ of adults (22 patients) stated a preference for SCIG over IVIG therapy and 83\% (20 patients) preferred home therapy over therapy at the clinic/physician. Only 1 patient preferred $\operatorname{Ig} G$ therapy in the clinic/physician setting. Two patients had no preferences regarding the route of $\operatorname{IgG}$ administration and 3 patients had no preference regarding location.

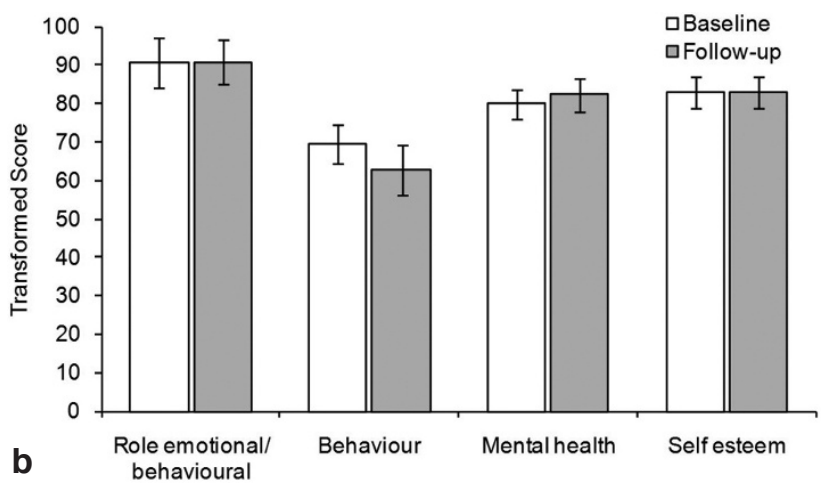

Fig. 3. CHQ-PF50 Scores for children $<14$ years in the HRQoL subpopulation at baseline (visit 1) and follow-up (visit 7). Mean and standard error data are shown $(\mathrm{N}=11$, except for the scale self esteem: $N=10)$. A score of 0 indicates the worst possible health state and 100 the best possible health state. * Statistically significant difference between baseline and follow-up ( $\mathrm{p} \leq 0.05)$. a) Physical subscales. b) Psychological subscales. c) Parental impact and family subscales.

\section{SAFETY}

During the course of the study, only 2 adverse drug reactions (local tissue reactions) were reported by 2 adult patients, neither of which was a severe systemic adverse event. One patient discontinued treatment because of the adverse event (reddening, swelling, local hyperthermia, impaired motility). No clinically relevant changes from baseline were observed in any of the serum chemistry or haematology parameters, or in any of the physical examination findings.

\section{DisCUSSION}

The current study evaluated the efficacy and safety of SCIG replacement therapy with Vivaglobin ${ }^{\circledR}$ under real-life conditions and described self-reported 
HRQoL in adults and children with antibody deficiencies.

Vivaglobin ${ }^{\circledR}$ therapy at doses equivalent to the previous IVIG dose resulted in mean $\operatorname{Ig} G$ trough levels that were significantly higher than those during IVIG treatment $(7.5 \mathrm{~g} / \mathrm{L}$ vs. $6.6 \mathrm{~g} / \mathrm{L} ; \mathrm{p}<0.01)$, confirming the previously reported beneficial effect of SCIG therapy in terms of normalized or increased serum $\operatorname{IgG}$ trough levels $[8,9,11,12,15]$, which is considered a contributing factor towards improving health and vitality $[27,28]$.

The investigators' assessment of the efficacy of SCIG therapy with Vivaglobin ${ }^{\circledR}$ was "excellent" in $89 \%$ of patients. In addition, the investigators assessed the administration of Vivaglobin ${ }^{\circledR}$ as "easy to learn and well feasible" in $82 \%$ of patients, and $86 \%$ of patients reported that SCIG therapy gave more flexibility than IVIG therapy. The high treatment satisfaction with SCIG therapy using Vivaglobin ${ }^{\circledR}$ concurs with earlier studies investigating switches from IVIG to SCIG [31, 32].

The HRQoL evaluation generally revealed clear results in favour of SCIG therapy with Vivaglobin ${ }^{\circledR}$, especially in the categories physical health (adults and children) and parental impact (children). Confirming results with Vivaglobin ${ }^{\circledR}$ therapy in clinical Phase III studies [19, 21], significant improvements with homebased SCIG treatment under real-life conditions were observed for the adults' evaluation of general health perceptions and vitality, as well as the parents' perception of the overall health status of their child, the emotional distress and limitations on personal time for the parents, and the limitations on family activities. Improvements in bodily pain for adults $(\mathrm{p}=0.02)$ have not been reported before. In contrast to the previous studies with Vivaglobin ${ }^{\circledR}$, no improvement in the CHQ-PF50 subscale role emotional/behaviour was found; the mean score at baseline was 91 and did not change at follow-up. In a recent study, Fasth and Nyström evaluated the parents' and children's perspective of HRQoL with SCIG treatment in 12 children and saw significant improvements in family activities from the parents' perspective [18]. The current study confirms this trend. Fasth and Nyström also reported improvements in mental health, for which only an insignificant improvement was seen in the current study, and in the item change in health, which was not assessed in the current study. Interestingly, Fasth and Nyström reported no significant improvements for parental impact [18]. Overall, SCIG therapy at home offers increased HRQoL comparable to that of agematched healthy controls [19, 27, 32]. It should be noted that the improvements in HRQoL observed in this study could be a result of switching from IVIG to SCIG, from hospital-based to home-based treatment, or a combination of both.

Assessments of treatment preferences revealed a clear trend in favour of SCIG therapy and home treatment. This trend concurs with earlier observations with Vivaglobin ${ }^{\mathbb{R}}$ where a clear majority of children or parents $(88 \%)$ and adults $(82 \%)$ preferred SCIG therapy [19].

In the current study, no severe systemic side-effects were observed during SCIG therapy with Vivaglobin ${ }^{\circledR}$, confirming the favourable safety profile in comparison to IVIG therapy reported previously $[9,29]$. Specifically, the low incidence of side-effects with SCIG therapy in children is important because side-effects are common with IVIG therapy in children and can cause significant morbidity [30]. Overall, SCIG therapy with Vivaglobin ${ }^{\circledR}$ was safe and well tolerated in patients with primary or secondary antibody deficiencies.

In conclusion, our results show that SCIG therapy with Vivaglobin ${ }^{\circledR}$ under real-life conditions is effective, safe, and well tolerated in patients with primary or secondary antibody deficiencies. The subcutaneous route allows self-administration at home and therefore enables a more independent lifestyle than with IVIG therapy. Patients in this study had a clear preference for SCIG therapy at home, which is reflected in significant improvements in HRQoL.

Acknowledgments: This study was sponsored by CSL Behring, Marburg, Germany. We sincerely thank Corinna Miede at Accovion GmbH, Marburg, Germany, for the statistical support. We thank the entire Vivaglobin ${ }^{\circledR}$ Study Group for their participation in the study. In addition to the authors, the following investigators have included at least 2 patients: Wolfram Ebell, Charité - Campus Virchow-Klinikum, Berlin; Bernd Gruhn, Klinik für Kinder- und Jugendmedizin, Jena; Georg Jacobs, Schwerpunktpraxis für Hämatologie und Onkologie, Saarbrücken; Birgit and Manfred Kindler, Onkologische Schwerpunktpraxis, Berlin; Wilma Mannhardt-Laakmann, Zentrum für Kinder- und Jugendmedizin, Mainz; Ove Peters, Krankenhaus Barmherzige Brüder, Regensburg; and Ilka Schulze, Charité - Campus Virchow-Klinikum, Berlin (during the conduct of this study). We are grateful to the nurses at the study centres who assisted the study by training and supervising the patients.

\section{REFERENCES}

1. Yong PF, Tarzi M, Chua I, et al. Common variable immunodeficiency: an update on etiology and management. Immunol Allergy Clin North Am. 2008; 28(2): 367-86, ix$\mathrm{x}$.

2. Pan-Hammarström Q, Hammarström L. Antibody deficiency diseases. Eur J Immunol. 2008; 38(2): 327-33.

3. Cunningham-Rundles C, Bodian C. Common variable immunodeficiency: clinical and immunological features of 248 patients. Clin Immunol. 1999; 92(1): 34-48.

4. Grimbacher B, Warnatz K, Peter HH. Der variable Immundefekt (Common variable immunodeficiency). 2003; http://www.cvid.info/de/BaxterUniFreiburg\%2072dpi.p df (Accessed: 26 Nov 2009).

5. Buckley RH. Primary immunodeficiency diseases: dissectors of the immune system. Immunol Rev. 2002; 185: 206-19.

6. Kirmse J. Subcutaneous administration of immunoglobulin. J Infus Nurs. 2006; 29(3 Suppl): S15-20.

7. Darabi K, Abdel-Wahab O, Dzik WH. Current usage of intravenous immune globulin and the rationale behind it: the Massachusetts General Hospital data and a review of the literature. Transfusion. 2006; 46(5): 741-53.

8. Radinsky S, Bonagura VR. Subcutaneous immunoglobulin infusion as an alternative to intravenous immunoglobulin. J Allergy Clin Immunol. 2003; 112(3): 630-3.

9. Gardulf A, Nicolay U, Asensio O, et al. Rapid subcutaneous IgG replacement therapy is effective and safe in children and adults with primary immunodeficiencies - a prospective, multi-national study. J Clinical Immunol. 2006; 26: 177-85. 
10. Weiler CR. Immunoglobulin therapy: history, indications, and routes of administration. Int J Dermatol. 2004; 43: 163-6.

11. Gardulf A, Andersen V, Björkander J, et al. Subcutaneous immunoglobulin replacement in patients with primary antibody deficiencies: safety and costs. Lancet. 1995; 345: 365-9.

12. Berger M. Subcutaneous immunoglobulin replacement in primary immunodeficiencies. Clin Immunol. 2004; 112: 1-7.

13. Gustafson R, Hammarström L. Subcutaneous immunoglobulin replacement therapy. Ellipse. 2002; 18: 45-8.

14. Gardulf A. Immunoglobulin treatment for primary antibody deficiencies: advantages of the subcutaneous route. BioDrugs. 2007; 21(2): 105-16.

15. Gaspar J, Gerritsen B, Jones A. Immunoglobulin replacement treatment by rapid subcutaneous infusion. Arch Dis Child. 1998; 79: 48-51.

16. Gardulf A, Björvell H, Andersen V, et al. Lifelong treatment with gammaglobulin to patients with primary antibody deficiencies: The patients' experiences of subcutaneous self-infusions and home therapy. J Adv Nurs. 1995; 21: 917-27.

17. Sigstad HM, Stray-Pedersen A, Frøland SS. Coping, quality of life, and hope in adults with primary antibody deficiencies. Health Qual Life Outcomes. 2005; 3: 31.

18. Fasth A, Nyström J. Quality of life and health-care resource utilization among children with primary immunodeficiency receiving home treatment with subcutaneous human immunoglobulin. J Clin Immunol. 2008; 28(4): $370-8$.

19. Gardulf A, Nicolay U, Asensio O, et al. Children and adults with primary antibody deficiencies gain quality of life by subcutaneous IgG self-infusions at home. J Allergy Clin Immunol. 2004; 114: 936-42.

20. Gardulf A, Nicolay U. Replacement IgG therapy and selftherapy at home improve the health-related quality of life in patients with primary antibody deficiencies. Curr Opin Allergy Clin Immunol. 2006; 6: 434-42.

21. Gardulf A, Borte M, Ochs HD, et al. Prognostic factors for health-related quality of life in adults and children with primary antibody deficiencies receiving SCIG home therapy. 2008; 126: 81-8.

22. Conference Report, Network of Rare Blood Disorder Organizations, Conference on Comprehensive Care for Rare Blood Disorders, February 3-5, 2006, Toronto, Ontario.

23. Abrahamsen TG, Sandersen H, Bustnes A. Home therapy with subcutaneous immunoglobulin infusions in children with congenital immunodeficiencies. Pediatrics. 1996; 98: 1127-31.
24. Ware JE Jr, Sherbourne CD. The MOS 36-item short form health survey (SF-36). I. Conceptual framework and item selection. Med Care. 1992; 30: 473-83.

25. Ware JE Jr, Snow KK, Kosinski M. SF-36 health survey: manual and interpretation guide. Lincoln (RI): QualityMetric Inc; 2000.

26. Landgraf J, Abetz L, Ware JE Jr. The Child Health Questionnaire (CHQ), a user's manual. 2nd ed. Boston: The Health Institute; 1999.

27. Gardulf A, Björvell H, Gustafson R, et al. The life situations of patients with primary antibody deficiency untreated or treated with subcutaneous gammaglobulin infusions. Clin Exp Immunol. 1993; 92(2): 200-4.

28. Nicolay U, Kiessling P, Berger M, et al. Health-related quality of life and treatment satisfaction in North American patients with primary immunodeficiency diseases receiving subcutaneous IgG self-infusions at home. J Clin Immunol. 2006; 26(1): 65-72.

29. Chapel HM, Spickett GP, Ericson D, et al. The comparison of the efficacy and safety of intravenous versus subcutaneous immunoglobulin replacement therapy. J Clin Immunol. 2000; 20(2): 94-100.

30. Singh-Grewal D, Kemp A, Wong M. A prospective study of the immediate and delayed adverse events following intravenous immunoglobulin infusions. Arch Dis Child. 2006; 91(8): 651-4.

31. Kittner JM, Grimbacher B, Wulff W, et al. Patients' attitude to subcutaneous immunoglobulin substitution as home therapy. J Clin Immunol. 2006; 26(4): 400-5.

32. Fasth A, Nyström J. Safety and efficacy of subcutaneous human immunoglobulin in children with primary immunodeficiency. Acta Paediatr. 2007; 96(10): 1474-8.

Received: February 1, 2010 / Accepted: May 19, 2010

Address for correspondence:

Florian Hoffmann, MD

University Children's Hospital

Paediatric Infectious Diseases and Immunology

Ludwig Maximilians University

Lindwurmstr. 4

81247 Munich

Germany

Tel.: $\quad+498951602811$

Fax: +498951607939

E-mail: Florian.Hoffmann@med.uni-muenchen.de 